\title{
Nurses' Perception of Organisational Justice and its Effect on Bullying Behaviour in the Hospitals of Turkey
}

\author{
Hanım Seyrek ${ }^{1}$, Dilek Ekici ${ }^{*}$ \\ ${ }^{1}$ Ankara Numune Research and Education Hospital, Ankara, Turkey \\ ${ }^{2}$ Nursing Department, Health Science Faculty, Gazi University, Ankara, Turkey \\ *Corresponding Author: Dilek Ekici, Ph.D., R.N., Associate Professor, Nursing Department, Health Science Faculty, \\ Gazi University, Besevler, Ankara, Turkey. Tel: 903122162623, Email: docdrdilekekici@gmail.com
}

Received July 11, 2017; Accepted August 16, 2017; Online Published September 2, 2017

\begin{abstract}
Background: The 'Organizational Justice' concept is used in order to determine whether the administrator is fair to his personnel or not. It is said that those who get bullied are usually terrorized, annoyed, excluded, belittled, deprived of resources, isolated and prevented from claiming rights.

Objective: The purpose of this study is to determine nurses' perception of organizational justice and its effect on the bullying behaviour they are exposed to.

Methods: The cross-sectional study was conducted on nurses at a university hospital and a private hospital in Ankara. In this regard, 250 nurses who had been serving in their respective hospitals for 6 months participated in the study. The variables were measured under 2 categories: bullying and perception of organizational justice. A simple regression analysis was carried out in order to determine the bullying behaviour which causes the nurses' justice perceptions.

Results: According to the survey, the nurses are most likely to perceive injustice in the area of distributional justice. Results revealed that the ratio of nurses who were exposed to bullying in the workplace was $28 \%$. There was a significant and negative relation between the nurses' distributional justice perception and the bullying they were exposed to.

Conclusion: The employees whose organizational justice perceptions are low, display a threatening and negative behaviour towards their colleagues and the institution. They feel themselves to be threatened when they think that they can't communicate with upper management respectfully and also when they believe that their managers are unjust in performance assessment, in assessing salaries and promotion.
\end{abstract}

Keywords: Nurses, Justice, Behaviour, Bullying

\section{Background}

The concept of 'Organisational Justice' is used in order to determine whether the administrator is fair to his personnel or not. ${ }^{1}$ Employees want to see how their gains come back to them (prize, award, promotion, etc), and how these decisions are taken, so they want to see how their efforts are assessed, and how they are informed. ${ }^{2-4}$ This results in an increased or decreased perception of justice within the institution. ${ }^{5,6}$ In this analysis of perception, people develop an attitude to their work, institution and administrator. ${ }^{7}$

Organisational justice is separated into 3 sections: distributive justice, procedural justice and interactional justice. ${ }^{1,8}$ Distributive justice is related to honesty and accuracy in the distribution of organisational resources. The perception of distributional justice is the belief that employees should receive an acknowledgement of their contribution to the institution's income and that it meets their own perception of the extent of their contribution. . $^{1,3,8}$ Procedural justice concerns what kind of method, procedure or policy is used to determine the physical facilities, rewards, working conditions and performance assessment etc of the personnel. ${ }^{1,3,8}$ In other words, it is just a perception about what extent honesty and accuracy is followed in the process of decision making. Interactional justice is related to the humanitarian side of institutional practice. Interactional justice has 2 sub-dimensions, called interpersonal and informing justice. ${ }^{1,6,8}$ Interpersonal justice is related to personnel being informed by the administrator about the way decisions are made, and the respect between junior and senior staff. ${ }^{2,8}$ Informational justice is widely used, from informing juniors about organisational processes, to social and other matters pertaining to employees, and also the protection of benefits, in respect of the justice of personnel's information giving. ${ }^{6,8}$

Copyright (C) 2017 The Author(s). This is an open-access article distributed under the terms of the Creative Commons Attribution License (http:// creativecommons.org/licenses/by/4.0), which permits unrestricted use, distribution, and reproduction in any medium, provided the original work is properly cited. 
Providing justice in institutions is the duty of the manager. In the last decade, many health professionals have perceived organizational justice with reference to applications of operational, informational and interpersonal justice at the public hospitals in our country.,8 Organisational justice perceptions can influence attitudes and behaviour for good or ill, in turn having a positive or negative impact on employee performance, interaction with co-workers and the workplace environment. ${ }^{4,5}$

The other concept is the concept of bullying which is as important as the concept of justice in business life. Bullying consists of behaviour aimed at a particular person to socially humiliate and stigmatise the victim..$^{6-8}$ By attacking the victim's character and professional competence, it actually targets sabotaging the victim's reputation. In workplaces, each person can experience psychological violence from managers, supervisors, co-workers or subordinates. ${ }^{9-11}$ The effects of intentional and systematically repeated psychological oppression show on victims as psychological damage accumulates over time. ${ }^{8,12,13}$ The adverse effects are felt not only by the staff member(s) targeted but also by the rest of the staff observing the process as they feel they might one day be the focus of such negative behaviour. They might also resort to unethical behaviour themselves to survive and to avoid being the victim. ${ }^{14,15}$

Victims of psychological violence are exposed to some attitudes and behaviour such as exclusion, humiliation, deprivation of some organisational facilities, isolation, injustice in the sharing of organisational facilities, restriction of institutional rights, gossip about untrue events and baseless rumours about mental problems. ${ }^{6,8,9}$ Bullying behaviour directly affects employees negatively, both the victim being bullied and the other employees around them. Employees may be exposed to bullying behaviour by their administrator, senior managers, and colleagues at the same level or even from junior colleagues. Actually, as senior managers consider psychologically violent attitudes as a normal part of the job of trying to control the junior employees and while employees are so accustomed to this negative behaviour, bullying is not reported by the employees in many health organisations. ${ }^{7,13,15}$

\section{Objective}

The aim of this study is to determine whether the nurses' perception of justice has an effect on the bullying behaviours they are exposed to in their work or not. Here are some research questions:

- To what extent do the nurses think they have been treated unjustly? Is there any difference between institutions?

- What are the content and the frequency of the bullying behaviour which the nurses are exposed to? Is there any difference between institutions?

- Is there an effect of the nurses' perception of organisational justice on the bullying behaviours they are exposed to?

\section{Methods}

This cross-sectional study took place in the hospitals in Ankara, Turkey and it took place in a university, a public and a private hospital. Stratified sampling study was used for sampling of the study. One hospital was chosen from university hospitals and the other was chosen from private hospitals. To these sampling hospitals, a written application was sent which emphasised the aim and the method of the study. A written approval was received from the university and private hospitals but not the public hospital. Data was collected from those who had been serving in their respective hospitals for 6 months and the willing nurses who joined the research. The nurses' verbal consent was given to the researcher. Also, participants were told their identity would be concealed and it was suggested to them that they fill the form in at a suitable time and place. The data were collected from the researchers. The anonymity of respondents was ensured. A data form was delivered to 221 nurses at the university hospital and to 129 nurses at the private hospital. Finally, 176 forms from the university hospital and 74 forms from the private hospital were completed. The answering rates were $79 \%$ and $57 \%$ at the university hospital and private hospital respectively. In total, 350 questionnaires were delivered and among them, 250 forms (71\%) were assessed.

\subsection{Data Collecting Tools}

The data form consisted of three sections. In the first section, the participants' demographic information (age, education, length of employment in nursing, length of time employed in current facility and position) were requested.

In the second section, the 'Organisational Justice Perception Scale' was used (consisting of 20 items) developed (4) and translated to Turkish language (2). The institution was assessed, using the scale on four dimensions, of whether it was just or unjust to employees (operational justice, procedural justice, interpersonal justice and informational justice). Likert's 6-point method was used in the definition of frequency of conduct ( 0 being the lowest, and 5 the highest point). While the higher points show a high sense of justice in the institution, the lower points show a low sense of justice in the institution. Cronbach a coefficient for this scale was 0.89 in this study.

In the third section, a 33-item tool developed by Dilek and Aytolan was used in order to measure the nurses' perception of bullying in workplaces. ${ }^{6}$ The nurses were asked to mark the frequency of each item within the last 12 months and to mark from whom every behaviour they had been exposed to had originated (supervisor, co-worker, subordinate, etc). This tool consisted of four sub-categories: 'individual's isolation from work', 'attack on professional status,' 'attack on personality' and 'direct attack.' The items were evaluated on a 6-point Likert-type scale from 0 ('I have never experienced') to 5 ('I constantly experience this'). The total received score was divided by the total number of items (total score/33). The number 
obtained over one showed that the employee had been intentionally exposed to psychologically violent behaviour. Cronbach a coefficient for this scale was 0.91 in this study.

\subsection{Analysis of the Data}

Statistical analysis of the data was done using the SPSS (15.0) program. Firstly, a defining statistic was used in the analysis of the data (frequency, percentage average, standard deviation). Whether the data to be used for parametric analysis had the normal distributions or not was analysed with the Kolmogorov Smirnov normal distributional congruity test. The Levene test was used to measure the difference between the 2 institutions' variance, and it was seen that these variances were equal $(P>0.05)$, and then the difference between the groups was analysed with an independent $t$ test. Pearson correlation and regression analyses were done in order to determine the factors related to psychologically violent behaviour.

\section{Results}

In total, 250 nurses participated in this study. Among them, 221 nurses were women, and $29 \mathrm{men}$. When we look at their education, we find that 48 nurses are graduates of a Health High School, 72 nurses are graduates with an associate degree, 126 nurses are graduates with a licence degree, and 4 nurses are graduates with a degree. The nurses' designated positions in the institutions are emphasised. Service head nurses number 31, (shift) charge nurses number 11, nurses' number 198, and health officers number 10 etc. Results showed that 74 nurses worked in the private hospital and 176 nurses worked in the university hospital.

\subsection{Nurses' Perception of Justice}

The nurses' perceptions of justice are given in Table 1. Accordingly, the employees' perception of justice is at the lowest degree in the area of distributional justice $(2.62 \pm$ $1.35)$. This is followed by operational justice $(2.95 \pm 0.85)$, interpersonal justice $(3.30 \pm 0.76)$, and informational justice $(3.49 \pm 1.04)$. The employees state that they are being treated unjustly about dimension of distributive justice "shown in the performance gains from compliance" and dimension of procedural justice "the implementation of the processes away from prejudices."

\subsection{The Difference Between the Institutions in Terms of Justice}

The differences between the private and university hospitals are shown in Table 1 in the extent of nurses' perception of justice. Accordingly, it's determined that there is no difference between the private $(2.86 \pm 1.38)$ and university hospitals $(2.52 \pm 1.33)$ in terms of distributional justice and it is shown that the distributional justice is low in both institutions. Also, it is recognised that the nurses' procedural justice ( $2.78 \pm 0.82)$, interpersonal justice (3.17 \pm 0.77 ) and informational justice is lower in the university hospital than the private one.
Table 1. The Difference Between the Institutions of Nurses' Perception of Organizational Justice

\begin{tabular}{|c|c|c|c|}
\hline Institution & $N$ & Mean \pm SD & $t$ test \\
\hline Processing Justice & & & $5.01^{\mathrm{a}}$ \\
\hline Total & 250 & $2.95 \pm 0.85$ & \\
\hline Private & 74 & $3.35 \pm 0.79$ & \\
\hline University & 176 & $2.78 \pm 0.82$ & \\
\hline Distribution Justice & & & 1.84 \\
\hline Total & 250 & $2.62 \pm 1.35$ & \\
\hline Private & 74 & $2.86 \pm 1.38$ & \\
\hline University & 176 & $2.52 \pm 1.33$ & \\
\hline Interpersonal Justice & & & $4.56^{a}$ \\
\hline Total & 250 & $3.30 \pm 0.76$ & \\
\hline Private & 74 & $3.63 \pm 0.65$ & \\
\hline University & 176 & $3.17 \pm 0.77$ & \\
\hline Informing Justice & & & $3.93^{\circ}$ \\
\hline Total & 250 & $3.49 \pm 1.04$ & \\
\hline Private & 74 & $3.88 \pm 0.91$ & \\
\hline University & 176 & $3.32 \pm 1.06$ & \\
\hline Justice Total & & & $5.13^{a}$ \\
\hline Total & 250 & $3.08 \pm 0.73$ & \\
\hline Private & 74 & $3.43 \pm 0.64$ & \\
\hline University & 176 & $2.93 \pm 0.71$ & \\
\hline
\end{tabular}

a $P<0.001$

\subsection{Exposure to Bullying}

Many of the nurses (90\%) who participated in the research had been exposed to psychologically violent behaviour once or more in the previous year. The content of the psychologically violent behaviour which the nurses were exposed to in the workplace is shown in Figure 1. The majority of these psychologically violent behaviours were insulting the professional status and the personality of the victim. When psychologically violent behaviour is observed in hospitals, the nurses were exposed to insults about their personality 'talking to them in humiliating and disrespectful ways' (62\%). The second most frequent attack is insulting the professional status of the victim, "both you and your work are checked secretly' (58\%) and 'you are blamed for work which you aren't responsible for' (56\%). Participants reported that they were exposed to these behaviours mostly by their own controllers, and then from their colleagues and even from junior staff.

The psychological violence frequency the nurses were exposed to is shown in Figure 2. Accordingly, while 30\% of the nurses did not have any trouble with psychologically violent behaviour (average score $0-0.25$ ), $28 \%$ of them were deliberately exposed to psychologically violent behaviour (average score $>1$ ). It must be emphasised that there is statistically a significant difference between the university hospital $(0.87 \pm 0.76)$ and private hospital $(0.43 \pm 0.50)$ that joined the research $(t=5.35 ; P>0.01)$. 


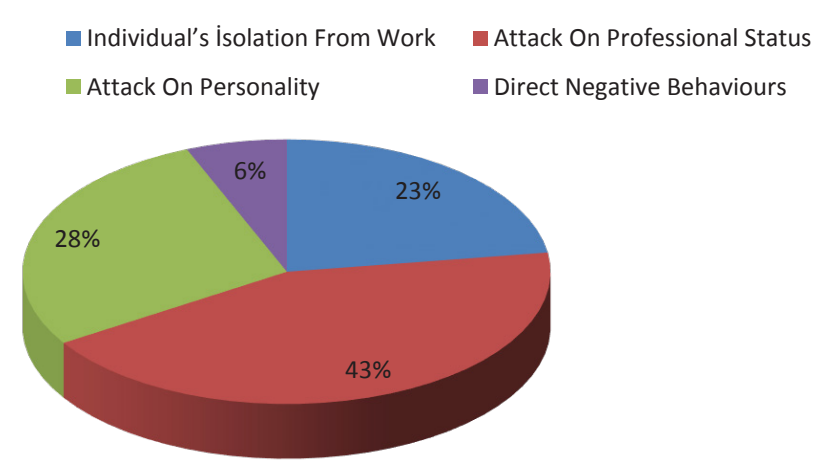

Figure 1. The Content of Nurses Exposed to Mobbing Behaviours $(\mathrm{N}=250)$.

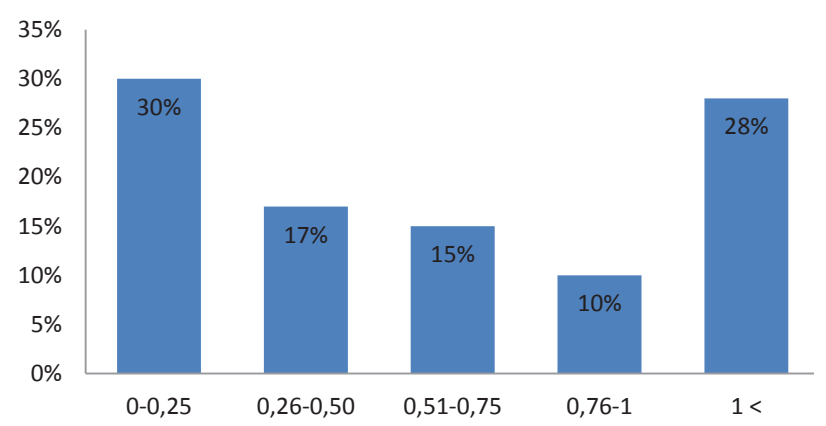

Figure 2. The Frequency of Nurses' Perception of Workplace Mobbing Behaviours $(\mathrm{N}=250)$.

4.4. The Difference between the Institutions in Terms of Bullying Behaviour

It has been observed that $91 \%$ of the nurses working in the university hospital, and $83 \%$ of the nurses working in the private hospital had been exposed to psychologically violent behaviour at least once or more in their workplace in the previous year. In the university and private hospital, the frequency of the bullying behaviour which the nurses were exposed to in the previous year is shown in Figure 3. Accordingly, while $42 \%$ of the nurses who work in the

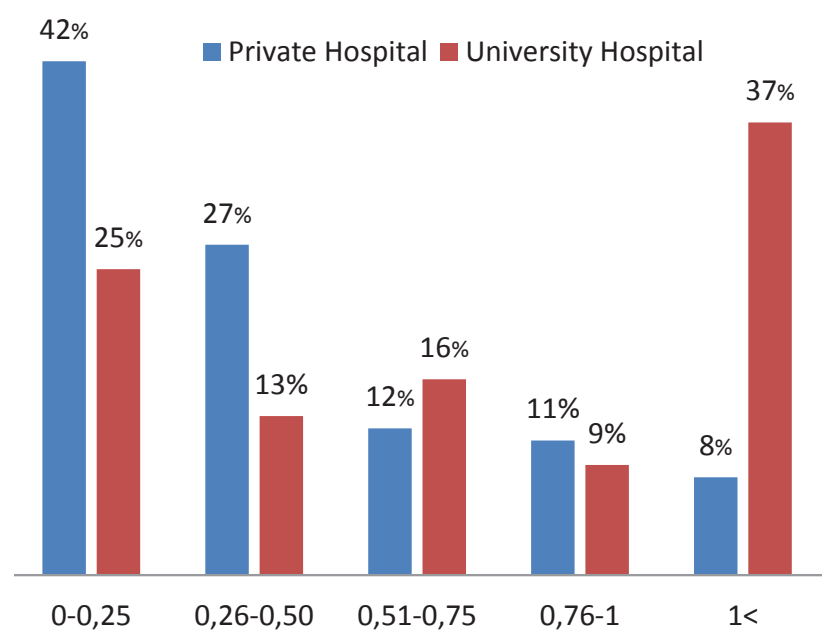

Figure 3. The Frequency of the Difference between the Institutions Mobbing Behaviors $(\mathrm{N}=250)$. private hospital had not experienced psychologically violent behaviour in their workplace in the previous year, $8 \%$ of the nurses were deliberately exposed to psychologically violent behaviour. While $25 \%$ of the nurses who work in the university hospital had never been exposed to psychologically violent behaviour in the previous year (average score $0-0.25$ ), 37\% of the nurses had been deliberately exposed to psychologically violent behaviour in the workplace in the previous year.

The differences among the nurses' exposure to bullying behaviour are given in Table 2. According to Table 2, it is statistically determined that nurses are more exposed to bullying behaviour such as the employees' isolation from their profession, attacking their professional status and personality, in the university hospital compared to the private hospital $(P<0.01)$.

4.5. The Effect of the Nurses' Organisational Justice Perception on the Bullying Behaviour they are Exposed to The justice perception of the nurses and the bullying behaviour they are exposed to have no statistically significant relation in terms of their age, educational level, their position, working duration in the institution and their professional working duration $(P>0.05)$. At the meanwhile, it was determined that there is a relation among the bullying behaviour the nurses are exposed to $(r=0.28, P<0.001)$ and the institution they work in and the organisational justice perception $(r=-0.31, P<0.001)$. Also, it was determined that there is a statistically negative and meaningful relation between the injustice the nurses perceive and the psychologically violent behaviour they are exposed to $(r=-0.36, P<0.001)$. Accordingly, as nurses' exposure to the bullying behaviour increased, their justice perception of the institution decreased.

A logistic regression analysis was carried out in order to determine the bullying behaviour which causes the nurses' justice perceptions to deteriorate. Organizational justice is used as a dependent variable, and type of the hospital and psychologically violent behaviours sub-groups are used as independent variables for the regression analysis. It was determined that psychologically violent behaviour and type of the hospital have a negative effect $(-49 \%)$ on the nurses' organisational justice perceptions (R: $0.703 ; \mathrm{R}^{2}$ : $-0.493 ; \mathrm{F}: 112.913 ; P<0.000$ ). Type of the hospital (working in the university hospital) is $21 \%$, "individual's isolation from work" is $34 \%$, and 'direct negative behaviour' is $12 \%$ having a negative effect on the nurses' organisational justice perception (Table 3).

\section{Discussion}

When the nurses gave marks from 1 to 5 to their institution in terms of its justice perception, it was determined that they generally perceived injustice $(2.62 \pm 1.35)$ in terms of distributional justice, and also it was determined that there is statistically no significant difference between the institutions $(t=1.84 ; P>0.05)$. The study shows that it is 
Table 2. The Difference Between the Institutions in Mobbing Behaviours

\begin{tabular}{lccc}
\hline Institution & N & Mean \pm SD & $t$ \\
\hline Individual's isolation from work & & & \\
Private & 74 & $0.30 \pm 0.51$ & \\
University & 176 & $0.76 \pm 0.86$ & $-5.18^{\mathrm{a}}$ \\
Attack on professional status & & & \\
Private & 74 & $0.66 \pm 0.75$ & \\
University & 176 & $1.27 \pm 1.04$ & $-5.21^{\mathrm{a}}$ \\
Attack on personality & & & \\
Private & 74 & $0.51 \pm 0.56$ & \\
University & 176 & $0.91 \pm 0.89$ & $-4.28^{\mathrm{a}}$ \\
Direct negative behaviours & & & \\
Private & 74 & $0.11 \pm 0.41$ & \\
University & 176 & $0.22 \pm 0.48$ & -1.76 \\
Total mobbing behaviours & & & \\
Private & 74 & $0.43 \pm 0.50$ & $-5.35^{\mathrm{a}}$ \\
University & 176 & $0.87 \pm 0.76$ & \\
\hline P & & & \\
\hline
\end{tabular}

a $P<0.00$.

Table 3. The Effect of the Mobbing Behaviours and Type of the Hospital on the Nurses' Organisational Justice Perception According to Linear Regression Analysis

\begin{tabular}{|c|c|c|c|c|}
\hline & B & $\beta$ & $t$ & $\boldsymbol{P}$ \\
\hline Type of hospital & -0.332 & -0.208 & -3.945 & 0.000 \\
\hline Individual's Isolation from work & -0.381 & -0.342 & -5.484 & 0.000 \\
\hline $\begin{array}{l}\text { Insulting to the professional } \\
\text { status }\end{array}$ & -0.310 & -0.084 & -0.867 & 0.221 \\
\hline Insulting to the personality & -0.073 & -0.061 & -1.130 & 0.187 \\
\hline Direct negative behaviours & -0.109 & -0.120 & -2.549 & 0.011 \\
\hline
\end{tabular}

unknown what criterions are enforced in the delivery of resources in many hospitals in our country and this delivery of resources is unfair. ${ }^{1,68}$ In other words, it was shown that the difference between the performance of the employees and their salary, promotion and their performance evaluation is not quite fair. Also, it was determined that the nurses who work in university hospitals are treated much more unjustly than the nurses who work in private hospitals in terms of operational justice, interpersonal justice and informational justice $(P<0.001)$.

In an institution, duty descriptions, work processes, performance assessment systems, description of the promotion and salary policy in a clear and detailed way and practising and informing the employees about them by the senior management are very important in constituting procedural and informational justice. According to the data, nurses who work in university hospitals perceive much more injustice due to some items such as: recognising how seniors assess employees' performance, knowing how the internal institutional process works, the items that are included in expressions concerning attitude and behaviour in interpersonal communication. It is said that a hospital's structure, organisation and operation is not peculiar to a work or professional group, it is dependent on an institutional culture or a manager's personal attitude and behaviour. While in private hospitals, work processes, the performance assessment system and duty descriptions are clearer and more detailed. This is while, in university hospitals there are none of these kinds of managerial substructures. So, it is obvious that there is a difference between the institutions.

Providing justice in institutions is the duty of the manager. The employees develop a justice perception of the institutions in observing whether the management are just or not. When the employees feel the institution is just, they perceive themselves as a valuable and respectful member of the institution, and they work productively and in harmony with their managers and colleagues. In contrast to this, if the manager delivers the duty rota and the resources in an unjust way, there may be conflict among the employees, and the employees may exhibit aggressive and despotic behaviour in order to remove this injustice. In the analysis we performed, working in university hospitals negatively affects nurses' justice perception $(-0.21 \%)$. Moreover, there is a statistically negative meaningful relation between the nurses' justice perceptions and the bullying behaviour they are exposed to in the institution $(r=-0.31 ; P<0.001)$. Also, it is said that the nurses' justice perception arises from the bullying behaviour (49\%) they are exposed to in workplaces.

Health professionals are known as the professional group who are at serious risk in terms of exposure to workplace bullying. ${ }^{6,9}$ It was actually seen that the majority of the nurses who joined the research $(83 \%$ of the nurses working in the private hospital and $91 \%$ of the nurses working in the university hospital), had been exposed to psychologically unjust violent behaviour once or more in the previous 12 months. This result corresponds with the literature and proves the fact that there is statistically meaningful difference between the nurses who work in university and private hospitals in terms of exposure to bullying behaviour $(P<0.05)$. It is more than clear that these attitudes frequently arise from their managers and colleagues. ${ }^{7,12-15}$

In health institutions, the psychologically violent behaviour that the nurses were exposed to frequently by their manager and his/her colleagues are: 'controlling the employees' performance secretly, humiliating the employees' performance/not appreciating them, hiding the required information for the work to be undertaken, burdening the nurse with extra work, behaving coldly, pretending not to see in the workplace, exclusion, humiliating, shouting or scolding, talking to them in an insulting and demeaning way and mocking them' and these overlap with our results (Figure 1). ${ }^{14,15}$ The aim is to make the employees feel unable to defend themselves, by shouting, scolding and humiliating them frequently 
in front of their colleagues or while they are with their patients. ${ }^{7}$ When the bullying behaviour is taken up one by one, apart from it being a negative behaviour, it can be tolerated once only, assuming the bully may be having a bad day. However, exposing employees to unjust criticism, some negative behaviour, including constant assault on the person or personality in front of a group or among others, can make it difficult to determine bullying definitely.

According to the research results, it was determined that the nurses who work in university hospitals face more employees' isolation from the job, and unacceptable behaviour aimed at professional and personal status than the nurses who work in private hospitals. In university hospitals, because of the injustices of operational justice, interpersonal justice and informational justice, it is thought that the employee may face much more psychologically violent behaviour. As for low justice perceptions, it might be possible that low administrative fairness is more commonly accepted as being somewhat part of organizational life. In other words, the possibilities of exposing the bullying behaviour of the nurses who work in private hospitals is lower than the nurses who work in university hospitals. It is obvious that the atmosphere and environment of private hospitals overcomes the difficult terms of nursing and as a result, makes nurses feel more fairness in organizations. Nurses have been considered as the key employees at health care organizations and as they have very close relationships with patients, their perception of justice must be seriously considered as they may affect the quality of care.

As a result, unfairness in health care organizations not only interrupts the order of treatments or health care services, but at the same time will destroy resources. ${ }^{5}$ Therefore, if justice is low, managers should first target intervention strategies towards improving these perceptions before attempting to display empowering practises.

\section{Conclusion}

The results of this study show that the distributional justice perceptions of the nurses are low in both hospitals. Meanwhile, it has been seen that the nurses' operational, informational and interpersonal justice perception is lower in the university hospital than the nurses who work in the private hospital. Also, the nurses who work in the university hospital are exposed to bullying behaviour much more in their workplace. In respect of the bullying behaviour, it is quite important that justice is enforced, and not only the conclusions but also the processes leading to that conclusion are clear. The employees whose organisational justice perceptions are low display threatening and negative behaviour towards their colleagues and the institution, and they feel themselves to be threatened when they think that they cannot communicate with upper management respectfully. They also think that their managers are unjust in performance assessment, in distributing salary and in promotion. Psychologically violent behaviour which the employees show each other will increase in situations where injustice is perceived.
Research Highlights

What Is Already Known?

Feeling of insecurity and restlessness caused by mobbing behaviours, which nurses have faced, create an extremely stressful and tense environment. Therefore, fair behaviours exhibited by nurse managers directly affects the culture perception of employees.

\section{What This Study Adds?}

This study shows that injustices arises from the executive structure and the operation of health institutions. Is is clearly obvious that nurses' exposure to psychologically violent behaviour is as a result of this.

Workplace bullying is an undesired condition in terms of both employees and organisations. Therefore, nurse managers should create a positive organisational justice perception among their personnel.

\section{Limitations}

One of the most important limitations of this study is the low number who participated in the research. The reason for this is that 45 of the 221 nurses' forms from the university hospital and 55 from the 129 nurses' surveys in the private hospital were invalid in the research, as the forms were incomplete, incorrect or the surveys were not filled. So, 100 of the 350 surveys which were delivered to the nurses who work in the university and private hospitals could not be completed at all or were incomplete because of workload or not finding extra time needed to fill in the survey. On the other hand, it would be quite normal for the employees to be unwilling to answer a survey on such a sensitive subject. This is due to the fact that justice perception and psychological violence in the workplace is still considered as a taboo subject in our country, and even talking about these subjects may create serious problems. It is assumed that the low numbers of the nurses who participated in the research mainly results from these factors.

\section{Authors' Contributions}

Study design: HS, DE; Data collecting: HS; Data analysis: DE, HS; Manuscript preparation: HS, DE.

\section{Conflict of Interest Disclosures}

The authors declared no potential conflicts of interest with respect to the research, authorship and/or publication of this article.

\section{Ethical Approval}

Not applicable.

\section{References}

1. Colquitt JA. On the dimensionality of organizational justice: a construct validation of a measure. J Appl Psychol. 2001;86(3):386-400. doi:10.1037/0021-9010.86.3.386.

2. Özmen ÖNT, Arbak Y, Özer PS. An inquiry about the effect 
of justice value on justice perception. Ege Academic Review. 2007;7(1):17-33

3. Heponiemi T, Elovainio M, Kouvonen A, et al. The effects of ownership, staffing level and organisational justice on nurse commitment, involvement, and satisfaction: a questionnaire study. Int J Nurs Stud. 2011;48(12):1551-1561. doi:10.1016/j. ijnurstu.2011.05.015.

4. Brunet L, Morin A, Savoie A, et. al. Empowering Employees: The Moderating Role of Perceived Organisational Climate and Justice. Can J Behav Sci. 2010:42(4);201-211. doi:10.1037/a0020465.

5. Hatam N, Fardid M, Kavosi Z. Perceptions of organizational justice among nurses working in university hospitals of shiraz: a comparison between general and specialty settings. Nurs Midwifery Stud. 2013;2(4):77-82. doi:10.5812/nms.10637.

6. Gür E. Organizational justice perception and burnout situations of nurses working in public, private and university hospitals [thesis]. Ankara: Gazi University Graduate School of Health Sciences; 2014

7. Liljegren M, Ekberg K. The associations between perceived distributive, procedural, and interactional organizational justice, self-rated health and burnout. Work. 2009;33(1):43-51. doi:10.3233/wor-2009-0842.

8. Özsoy Z, Ekici D. Perception of Nurses Regarding Organizational Justice and Ethical Behavior; Organızational Culture in Hospitals. Hosp Pract Res. 2017;2(2):41-46. doi:10.15171/hpr.2017.11.

9. Dilek Y, Aytolan Y. Development and psychometric evaluation of workplace psychologically violent behaviours instrument. J Clin Nurs. 2008;17(10):1361-1370. doi:10.1111/j.13652702.2007.02262.x.
10. Yildirim D. Bullying among nurses and its effects. Int Nurs Rev. 2009;56(4):504-511. doi:10.1111/j.1466-7657.2009.00745.x.

11. Yildirim D, Yildirim A, Timucin A. Mobbing behaviors encountered by nurse teaching staff. Nurs Ethics. 2007;14(4):447-463. doi:10.1177/0969733007077879.

12. Yıldıım D, Yıldırım A. Sağlık Alanında Çalışan Akademisyenlerin Karşılaştıkları Psikolojik Şiddet Davranışları ve Bu Davranışların Etkileri (Mobbing behaviors encountered by health science faculties staff and their responses to them). Türkiye Klinikleri Tıp Bilimleri Dergisi. 2010:30(2):559-570. doi:10.5336/medsci.2008-9832.

13. Cleary $M$, Hunt GE, Horsfall J. Identifying and addressing bullying in nursing. Issues Ment Health Nurs. 2010;31(5):331335. doi:10.3109/01612840903308531.

14. Murray JS. Workplace bullying in nursing: a problem that can't be ignored. Med Surg Nurs. 2009;18(5):273-276.

15. Stebbing J, Mandalia S, Portsmouth S, et al. A questionnaire survey of stress and bullying in doctors undertaking research. Postgrad Med J. 2004;80(940):93-96. doi:10.1136/ pmj.2003.009001.

16. Ekici D, Beder A. The effects of workplace bullying on physicians and nurses. Aust J Adv Nurs. 2014;31 (4):24-33.

17. Rutherford A, Rissel C. A survey of workplace bullying in a health sector organisation. Aust Health Rev. 2004;28(1):65-72. doi:10.1071/AH040065.

18. Yildirim A, Yildirim D. Mobbing in the workplace by peers and managers: mobbing experienced by nurses working in healthcare facilities in Turkey and its effect on nurses. J Clin Nurs. 2007;16(8):1444-1453. doi:10.1111/j.13652702.2006.01814.x. 